\title{
Penerapan Data Mining Dalam Pengelompokan Data Member Card Mitra10 Untuk Meningkatkan Rewards Terhadap Konsumen dengan Metode Fuzzy Subtractive Clustering
}

\author{
Yudi Wibowo \\ Program Studi Teknik Informatika, Fakultas Ilmu Komputer dan Teknologi Informasi, Universitas Budi Darma \\ Jalan Sisingamangaraja No. 338, Medan, Sumatera Utara, Indonesia \\ Email: yudiwibowo909@gmail.com
}

\begin{abstract}
Abstrak-Pengelompokan data pada member card mitra Mitra10 hanya berdasarkan hari transaksi konsumen saja. Dan nilai poinnya hanya berdasarkan perhitungan $0,25 \%$ dari setiap transaksi. Tentu hal ini kurang efisien mengingat banyaknya data yang masih bisa dikelompokan untuk meningkatkan rewards bagi konsumen. Untuk mengelompokkan data nilai poin member card, maka terlebih dahulu harus menggunakan metode pengelompokan data yang sesuai. Pemilihan metode sangat berpengaruh terhadap hasil pengelompokan data. Setelah semua data member card Mitra10 ditransfomasikan ke dalam bentuk angka, maka data-data tersebut bisa dikelompokkan ke dalam algoritma fuzzy subtractive clustering. Untuk dapat melakukan pengelompokkan data-data tersebut menjadi beberapa cluster perlu dilakukan beberapa langkah, yaitu : Tentukan jumlah cluster yang diinginkan. Dalam penelitian ini data-data yang akan dikelompokan menjadi tiga cluster.Tentukan titik pusat awal dari setiap cluster. Dalam penelitian ini titik pusat awal ditentukan secara random dan didapat titik pusat dari setiap cluster. Suatu data akan menjadi anggota dari suatu cluster yang memiliki jarak terkecil dari pusat cluster nya. Misalkan untuk data pertama, jarak terkecil diperoleh pada cluster 1, sehingga data pertama akan menjadi anggota dari cluster 1. Demikian juga untuk data kedua, jarak terkecil ada pada cluster 3, maka data tersebut akan masuk pada cluster 3. Pada iterasi ini, titik pusat dari setiap cluster yang tidak berubah dan tidak ada data yang berpindah antar cluster, sebagai berikut : Hasil cluster 1 : Memiliki pusat $(1,413,1,195,1,695)$ terlihat bahwa karakteristik member card pada cluster 1 didominasi oleh member dengan golongan Bronze. Hasil cluster 2 : Memiliki pusat $(2,658,1,219,1,585)$ terlihat bahwa karakteristik member card pada cluster 2 didominasi oleh member dengan golongan Silver. Hasil cluster 3 : Memiliki pusat $(4,1.8,3)$ terlihat bahwa karakteristik member card pada cluster 3 didominasi oleh member dengan golongan Silver.
\end{abstract}

Kata Kunci: Member Card, Data Mining, Fuzzy Subtractive Clustering

\begin{abstract}
Data clustering of Mitra10 member card, it is only based on the payment day by customer. And the total point only based on $0,25 \%$ calcutation of each payment. This is not so efficient knowing that there are so many ungrouping data that can be use for increase the rewards to the customer. In order to clustering the data of member card total point, it need a method of data clustering. The method election really affecting the result of data clustering. After all of the member card Mitra10 data transformed to the number form, then the datas can be grouping to fuzzy subtractive clustering algorythm. The data need to divided to some cluster : Select the amount of the cluster. In this research the data will be divided to 3 cluster. Select the center point of each cluster and fisrt center point selected randomly to generate main center point of each cluster. One data will be part of one cluster that has the smallest distance from the center cluster. Example for the first data, smallest distance get by cluster 1, so that the first data will be member of cluster 1 . And so for the second data, smallest distance in cluster 3, so it will be member of cluster 3 . In this iteration, center point of each cluster does not changed and there is no moving data to another cluster. Cluster 1 result: Has center $(1,413,1,195,1,695)$ cluster 1 dominated by the bronze group. Cluster 2 result: Has center $(2,658,1,219,1,585)$ cluster 2 dominated by the silver group. Cluster 3 result: Has center $(4,1,8,3)$ cluster 3 dominated by the silver group.
\end{abstract}

Keywords: Member Card; Data Mining; Fuzzy Subtractive Clustering

\section{PENDAHULUAN}

Konsumen adalah setiap orang pemakai barang dan atau jasa yang tersedia dalam masyarakat, baik bagi kepentingan diri sendiri, keluarga, orang lain, maupun makhluk hidup lain. Jika dilihat dari perilaku konsumen dalam mengonsumsi suatu barang, dapat dibedakan menjadi dua macam, yaitu perilaku konsumen rasional dan perilaku konsumen irasional. Perilaku konsumen rasional adalah suatu konsumsi yang dapat dikatakan rasional jika memerhatikan hal-hal seperti, barang tersebut dapat memberikan kegunaan optimal bagi konsumen. Sedangkan perilaku konsumen irasional adalah suatu perilaku dalam mengonsumsi yang dapat dikatakan tidak rasional jika konsumen tersebut membeli barang tanpa dipikirkan kegunaannya terlebih dahulu.

Retail atau biasa disebut pengecer merupakan pelaku usaha yang menjual kebutuhan pokok sehari hari kepada para konsumen. Konsumen retail harus mendapatkan hak-haknya, konsumen berhak mendapatkan informasi harga yang wajar, seperti diskon, obral dan sebagainya. Konsumen juga berhak mencoba produk atau barang yang akan dibeli, berhak mengembalikan barang bila terdapat cacat yang tersembunyi, berhak mendapatkan pengembalian uang dengan alat tukar yang sah (uang), berhak menolak donasi yang ditawarkan pihak retail dan berhak mendapatkan produk yang halal. Saat ini banyak perusahaan retail mengeluarkan kartu keanggotaan untuk memanjakan pelanggannya. Jika konsumen memiliki kartu membership dari perusahaan retail tertentu, maka akan mendapatkan perlakuan istimewa seperti mendapat beragam hadiah, poin yang bisa ditukarkan, diskon khusus atau harga spesial. Program membership seperti ini merupakan strategi promosi dari perusahaan untuk mempertahankan pelanggannya. Perusahaan retail seperti supermarket, pusat perbelanjaan, SPBU, toko buku sampai café menggunakan strategi ini.

Pengelompokan (Clustering) merupakan salah satu teknik yang paling penting dalam Data Mining. Salah satu metode pengelompokan yang paling sering digunakan adalah Fuzzy C-Means. Metode Fuzzy C-Means memiliki beberapa 
karakteristik, antara lain membutuhkan banyaknya kelompok dan matriks keanggotaan kelompok yang ditetapkan sebelumnya. Biasanya, matriks keanggotaan kelompok awal diinisialisasikan secara acak yang menyebabkan metode Fuzzy C-Means memiliki kerumitan. Alternatif metode pengelompokan lainnya yang dapat digunakan jika jumlah kelompok tidak diketahui sebelumnya adalah metode Fuzzy Subtractive Clustering . Fuzzy Subtractive Clustering memperoleh hasil yang lebih konsisten dibandingkan dengan Fuzzy C-Means. Selain itu, Fuzzy Substractive Clustering memiliki kecepatan yang lebih baik dibandingkan Fuzzy C-Means, namun Fuzzy Subtractive Clustering memiliki akurasi yang lebih rendah dibandingkan dengan Fuzzy C-Means. Database yang dikenal dengan istilah Knowledge Discovery in Database (KDD) (Sutrisno, dkk. 2013). Teknik Data Mining yang digunakan untuk mencari segmentasi konsumen adalah menggunakan teknik clustering. Teknik clustering digunakan pada Data Mining untuk mengelompokkan 3 objek-objek yang memiliki kemiripan dalam kelas atau segmen yang sama, sementara objek-objek yang terletak pada kelas yang berbeda menunjukkan karakteristik yang berbeda juga.

\section{METODOLOGI PENELITIAN}

\subsection{Data Mining}

Data mining adalah suatu istilah yang digunakan untuk menguraikan penemuan pengetahuan di dalam database. Data mining adalah proses yang menggunakan teknik statistik, matematika, kecerdasan buatan, dan mesin pembelajaran untuk mengekstraksi dan mengidentifikasi informasi yang bermanfaat dan pengetahuan yang terkait dari berbagai database besar. Berikut ini beberapa definisi data mining dikutip dari beberapa sumber[3] : "Data mining adalah serangkaian proses untuk menggali nilai tambah dari suatu kumpulan data berupa pengetahuan yang selama ini tidak diketahui secara manual." "Data mining adalah analisis dari peninjauan kumpulan data untuk menemukan hubungan yang tidak diduga dan meringkas data dengan cara yang berbeda dengan sebelumnya, yang dapat dipahami dan bermanfaat bagi pemilik data." Sedangkan pengertian data mining menurut penulis adalah suatu proses pengelompokan data-data yang sangat besar dan bertujuan untuk mendapatkan hubungan atau pola yang memberikan manfaat.

\subsection{Fuzzy Subtractive Clustering}

Fuzzy subtractive clustering adalah algoritma clustering yang tidak terawasi, sebab pada fuzzy subtractive clustering kita harus terlebih dahulu menentukan banyaknya cluster yang akan dibentuk. Menentukan banyaknya cluster yang tepat merupakan permasalahan utama dalam pendekatan ini[7]. Apabila banyaknya cluster yang belum diketahui, maka kita harus menggunakan algoritma yang takterawasi (banyaknya cluster ditentukan oleh algoritma). Fuzzy subtractive clustering merupakan algoritma cluster yang tak terawasi yang diperkenalkan pertama kali oleh Chiu pada tahun 1994[7].

\section{HASIL DAN PEMBAHASAN}

Pada data nilai poin terlebih dahulu dilakukan pembagian nilai yang menjadi beberapa bagian nilai, yaitu :

Nilai $>300.000$

Nilai 200.000-299.000

Nilai $100.000-199.000$

Nilai 0-99.000

Kemudian nilai-nilai poin tersebut diurutkan dari yang terbesar berdasarkan frekuensi.

Setelah itu nilai poin yang memiliki frekuensi terbesar diberi inisial Platinum, nilai poin yang memiliki frekuensi terbesar kedua diberi inisial Gold dan nilai poin yang memiliki frekuensi terbesar ketiga diberi inisial Silver serta nilai poin yang memiliki frekuensi terbesar keempat diberi inisial Bronze. Hasil dari inisialisasi nilai poin dapat dilihat pada tabel 3.1

Tabel 1. Inisialisasi Data Nilai Hasil Seleksi

\begin{tabular}{lll}
\hline Nilai Poin Member & Frekuensi & Inisial \\
\hline$>300.000$ & 3 & Platinum \\
$200.000-299.000$ & 5 & Gold \\
$100.000-199.000$ & 7 & Silver \\
$0-99.000$ & 85 & Bronze \\
\hline
\end{tabular}

Selain nilai poin, tanggal bergabung juga termasuk kedalam jenis data yang perlu diinisialisasikan. Untuk melakukan inisialisasi data member dilakukan dengan langkah-langkah sebagai berikut :

Pada data tanggal bergabung terlebih dahulu dilakukan pembagian data yang menjadi beberapa bagian data, yaitu: Tahun 2010

Tahun 2011

Tahun 2012

Tahun 2013

Tahun 2014 


\section{TIN: Terapan Informatika Nusantara}

Vol 2, No 8, Januari 2022, Hal 471-475

ISSN 2722-7987 (Media Online)

Website https://ejurnal.seminar-id.com/index.php/tin

DOI 10.47065/tin.v2i8.993

Tahun 2015

Tahun 2016

Tahun 2017

Kemudian nilai-nilai tersebut diurutkan dari yang terbesar berdasarkan frekuensi.

Setelah itu nilai yang memiliki frekuensi tahun terendah diberi inisial 1, nilai yang memiliki frekuensi tahun terendah kedua diberi inisial 2 dan nilai yang memiliki frekuensi tahun terendah ketiga diberi inisial 3 dan seterusnya. Hasil dari inisialisasi tahun bergabung dapat dilihat pada tabel 2.

Tabel 2. Inisialisasi Tahun Bergabung

\begin{tabular}{ccc}
\hline Tahun Bergabung & Frekuensi & Inisial \\
\hline Tahun 2010 & 13 & 1 \\
Tahun 2011 & 19 & 2 \\
Tahun 2012 & 12 & 3 \\
Tahun 2013 & 12 & 4 \\
Tahun 2014 & 11 & 5 \\
Tahun 2015 & 13 & 6 \\
Tahun 2016 & 7 & 7 \\
Tahun 2017 & 13 & 8 \\
\hline
\end{tabular}

\subsection{Penerapan Metode Fuzzy Subtractive Clustering}

Setelah semua data member card Mitra10 ditransfomasikan ke dalam bentuk angka, maka data-data tersebut bisa dikelompokkan ke dalam algoritma fuzzy subtractive clustering. Untuk dapat melakukan pengelompokkan data-data tersebut menjadi beberapa cluster perlu dilakukan beberapa langkah, yaitu :

1. Tentukan jumlah cluster yang diinginkan. Dalam penelitian ini data-data yang akan dikelompokan menjadi tiga cluster.

2. Tentukan titik pusat awal dari setiap cluster. Dalam penelitian ini titik pusat awal ditentukan secara random dan didapat titik pusat dari setiap cluster.

Cluster 2 : diambil dari data ke-39

Cluster 1 : diambil dari data ke-25

Cluster 3 : diambil dari data ke-65

Tempatkan setiap data pada cluster, untuk mengetahui cluster mana yang paling dekat dengan data, maka perlu dihitung jarak setiap data dengan titik pusat setiap cluster :

Berdasarkan hasil perhitungan di atas didapatkan hasil bahwa jarak data member card pertama paling dekat adalah dengan cluster 1, sehingga data member card pertama di masukkan ke dalam cluster 1 (C1).

a. Menghitung jarak data ke-1 dengan centroid pertama (C1)

$$
\begin{aligned}
& \begin{aligned}
d(1,1) & =\sqrt{(1-1)^{2}+(1-1)^{2}+(2-1)^{2}} \\
& =\sqrt{(0)+(0)+(1)} \\
& =\sqrt{1}
\end{aligned} \\
& d(1,1)=1 \\
& d(2,1)=\sqrt{(1-1)^{2}+(1-1)^{2}+(1-1)^{2}}=0 \\
& d(3,1)=\sqrt{(2-1)^{2}+(1-1)^{2}+(3-1)^{2}}=2.236 \\
& d(4,1)=\sqrt{(1-1)^{2}+(1-1)^{2}+(2-1)^{2}}=1 \\
& d(5,1)=\sqrt{(2-1)^{2}+(1-1)^{2}+(2-1)^{2}}=1,414 \\
& d(6,1)=\sqrt{(2-1)^{2}+(1-1)^{2}+(1-1)^{2}}=1 \\
& d(7,1)=\sqrt{(4-1)^{2}+(2-1)^{2}+(1-1)^{2}}=3,162 \\
& d(8,1)=\sqrt{(3-1)^{2}+(2-1)^{2}+(1-1)^{2}}=2,236 \\
& d(9,1)=\sqrt{(1-1)^{2}+(1-1)^{2}+(1-1)^{2}}=0 \\
& d(10,1)=\sqrt{(4-1)^{2}+(1-1)^{2}+(1-1)^{2}}=3
\end{aligned}
$$




\section{TIN: Terapan Informatika Nusantara}

Vol 2, No 8, Januari 2022, Hal 471-475

ISSN 2722-7987 (Media Online)

Website https://ejurnal.seminar-id.com/index.php/tin

DOI 10.47065/tin.v2i8.993

Hasil perhitungan data ke-1 dengan centroid pertama (C1) selengkapnya untuk data member card Mitra10 bisa dilihat pada tabel akhir.

b. Menghitung jarak data ke-1 dengan centroid kedua (C2)

$$
\begin{aligned}
& =\sqrt{(4)+(0)+(1)} \\
d(1,2) & \equiv \sqrt{(1-3)^{2}+(1-1)^{2}+(2-1)^{2}} \\
d(1,2) & =2,236 \\
d(2,2) & =\sqrt{(1-3)^{2}+(1-1)^{2}+(1-1)^{2}}=2 \\
d(3,2) & =\sqrt{(2-3)^{2}+(1-1)^{2}+(3-1)^{2}}=2,236 \\
d(4,2) & =\sqrt{(1-3)^{2}+(1-1)^{2}+(2-1)^{2}}=2,236 \\
d(5,2) & =\sqrt{(2-3)^{2}+(1-1)^{2}+(2-1)^{2}}=1,414 \\
d(6,2) & =\sqrt{(2-3)^{2}+(1-1)^{2}+(1-1)^{2}}=1 \\
d(7,2) & =\sqrt{(4-3)^{2}+(2-1)^{2}+(1-1)^{2}}=1,414 \\
d(8,2) & =\sqrt{(3-3)^{2}+(2-1)^{2}+(1-1)^{2}}=1 \\
d(9,2) & =\sqrt{(1-3)^{2}+(1-1)^{2}+(1-1)^{2}}=2 \\
d(10,2) & =\sqrt{(4-3)^{2}+(1-1)^{2}+(1-1)^{2}}=1
\end{aligned}
$$

Hasil perhitungan data ke-1 dengan centroid kedua (C2) selengkapnya untuk data member card Mitra10 bisa dilihat pada tabel akhir.

c. Menghitung jarak data ke-1 dengan centroid ketiga (C3)

$$
\begin{aligned}
d(1,3) & =\sqrt{(1-4)^{2}+(1-2)^{2}+(2-4)^{2}} \\
& =\sqrt{(9)+(1)+(4)} \\
& =\sqrt{14} \\
d(1,3) & =3,741 \\
d(2,3) & =\sqrt{(1-4)^{2}+(1-2)^{2}+(1-4)^{2}}=4,358 \\
d(3,3) & =\sqrt{(2-4)^{2}+(1-2)^{2}+(3-4)^{2}}=2,449 \\
d(4,3) & =\sqrt{(1-4)^{2}+(1-2)^{2}+(2-4)^{2}}=3,741 \\
d(5,3) & =\sqrt{(2-4)^{2}+(1-2)^{2}+(2-4)^{2}}=3 \\
d(6,3) & =\sqrt{(2-4)^{2}+(1-2)^{2}+(1-4)^{2}}=3,741 \\
d(7,3) & =\sqrt{(4-4)^{2}+(2-2)^{2}+(1-4)^{2}}=3 \\
d(8,3) & =\sqrt{(3-4)^{2}+(2-2)^{2}+(1-4)^{2}}=3,162 \\
d(9,3) & =\sqrt{(1-4)^{2}+(1-2)^{2}+(1-4)^{2}}=4,358 \\
d(10,3) & =\sqrt{(4-4)^{2}+(1-2)^{2}+(1-4)^{2}}=3,162
\end{aligned}
$$

Hasil perhitungan data ke-1 dengan centroid kedua (C3) selengkapnya untuk data member card Mitra10 bisa dilihat pada tabel akhir. 


\section{TIN: Terapan Informatika Nusantara}

Vol 2, No 8, Januari 2022, Hal 471-475

ISSN 2722-7987 (Media Online)

Website https://ejurnal.seminar-id.com/index.php/tin

DOI 10.47065/tin.v2i8.993

Dari hasil perhitungan menggunakan RapidMiner maka data yang tergabung dalam anggota masing-masing cluster akan mendapatkan peningkatan rewards yang berbeda-beda. Peningkatan pemberian rewards akan melalui kebijakan manajemen Mitra10 Medan berupa :

1. Cluster_O

a. Nilai poin akan dikali 2 (dua)

b. Voucher belanja Rp. 50.000,-

c. Goodie Bag senilai Rp. 150.000,-

2. Cluster_1
a. Nilai poin akan dikali 3 (tiga)
b. Voucher belanja Rp. 100.000,-
c. Goodie Bag senilai Rp. 200.000,-

3. Cluster_2
a. Nilai poin akan dikali 4 (empat)
b. Voucher belanja Rp. 150.000,-
c. Goodie Bag senilai Rp. 250.000,-

\section{KESIMPULAN}

Dari hasil penelitian disimpulkan bahwa metode Fuzzy Subtractive Clustering dapat mengelompokan data member card Mitra10. Pembagian kategori berdasarkan data-data nilai poin dan tanggal bergabung, kemudian akan dikategorikan menjadi member bronze, silver, gold dan platinum, dengan melakukan penyelarasan menggunakan promotion mix dengan melihat nilai -nilai yang didapat pada setiap cluster. Metode Fuzzy Subtractive Clustering pada RapidMiner dimulai dengan penginputan data member card Mitra10 menjadi database pada Ms. Excel dengan ekstensi CSV. Data dengan jarak terdekat menyatakan anggota cluster tersebut, dilakukan perhitungan kembali sampai data tidak berpindah pada cluster lain, untuk meminimalkan fungsi objektif.

\section{REFERENCES}

[1] Vianti Mala Anggraeni Kusuma, M. Tanzil Furqon dan Lailil Muflikhah, "Implementasi Metode Fuzzy Subtractive Clustering Untuk Pengelompokan Data Potensi Kebakaran Hutan/Lahan.”, Jurnal Pengembangan Teknologi Informasi dan Ilmu Komputer, No. e-ISSN: 2548-964X

[2] I Gede Oka Artawan, G.K. Gandhiadi dan Tjokorda Bagus Oka, "Penentuan Lokasi SMP Baru di Kabupaten Klungkung dengan Algoritma Fuzzy Subtractive Clustering.”, Jurnal Matematika, Vol. 3 No. 2, Desember 2013. No. ISSN : 1693-1394

[3] Kusrini dan Emha Taufiq Luthfi, "Algoritma Data Mining" $2010: 3$

[4] Goldie Gunadi, Dana Indra Sensuse, "Discovering Knowledge in Data : An Introduction to Data Mining"

[5] Feri Sulianta dan Dominikus Juju, "Data Mining - Meramalkan Bisnis Perusahaan”, 2010

[6] Eko Prasetyo, "Data Mining : Konsep dan Aplikasi Menggunakan Matlab”, 2010

[7] Kusumadewi dan Purnomo $(2004,39)$

[8] Kusumadewi dan Purnomo dalam Yanti Novita $(2006,42)$

[9] Denis Aprilia C, Donny Aji Baskoro, Lia Ambarwati, I Wayan Simri Wicaksana, "Belajar Data Mining Dengan RapidMiner", 2013 